The exact relationship between ulcerative colitis and auto-immune haemolytic anaemia in these two cases is not known and it is possible that it is fortuitous. However, since there is evidence that both diseases have an immunological basis, it would seem likely that the cause of the two conditions is in some way linked. In any event, it is important to consider haemolysis as a cause of anaemia in ulcerative colitis.

\section{References}

Broberger, O. \& Perlmann, P. (1959) Autoantibodies in human ulcerative colitis. Journal of Experimental Medicine, $110,657$.

Davie, J.V. (1962) The Haemolytic Anaemias II, p. 343. J. A. Churchill Ltd, London.

Edwards, F.C. \& Truelove, J.C. (1964) The course and prognosis of ulcerative colitis. III. Complications. Gut, $\mathbf{5}, 1$.

Lorber, M., Schwartz, L.I. \& Wasserman, L.R. (1955) Association of antibody-coated red blood cells with ulcerative colitis. American Journal of Medicine, 19, 887.

Postgraduate Medical Journal (June 1975) 51, 411-412.

\title{
Gastric carcinoma and Turner's syndrome
}

\author{
D. SIEGLER \\ M.B., M.R.C.P. \\ Royal Free Hospital, London NW3
}

\begin{abstract}
Summary
The case is described of a gastric carcinoma developing in a 34-year-old female with Turner's syndrome. The association has not been previously reported. The literature on the appearance of malignant disease in disorders of the sex chromosomes is reviewed.
\end{abstract}

\section{History}

An unmarried 34-year-old female was first seen in February 1973, with a 3-week history of dull epigastric pain relieved by food, vomiting but no haematemesis, weakness, effort dyspnoea and thirst and polyuria. She had never had a menstrual period. On examination she was obviously anaemic and had many external stigmata of Turner's syndrome, including short stature $(148.6 \mathrm{~cm})$, scanty pubic and axillary hair, numerous pigmented naevi, undeveloped breasts, a low hair-line at the back of the neck, and was mentally subnormal. There was a soft apical pansystolic murmur. Routine urine testing revealed $2 \%$ glycosuria.

\section{Investigations}

Haemoglobulin $6.7 \mathrm{~g} / 100 \mathrm{ml}$; MCHC 28; WBC $7000 / \mathrm{mm}^{3}$; platelet count normal; serum and red cell folate, serum B12, urea and electrolytes, liver function tests, protein-bound iodine, total proteins and electrophoretic strip and chest $X$-ray were all normal; a buccal smear showed the typical chromosome count of Turner's syndrome (45XO).

Barium meal and swallow were normal; an IVP revealed bilateral duplex pelvi-calyceal and ureteric systems; a skeletal survey was normal except for unfused iliac epiphyses and spina bifida occulta of S1 and S2; gastroscopy and sigmoidoscopy were nor- mal; a glucose tolerance curve was of diabetic type; serum iron was reduced to $55 \mu \mathrm{g} / 100 \mathrm{ml}$ with a TIBC of $480 \mu \mathrm{g} / 100 \mathrm{ml}$.

A diagnosis of iron deficiency anaemia of undetermined aetiology was made.

\section{Treatment}

She was treated with oral ferrous sulphate with a resultant $20 \%$ reticulocytosis and a return of haemoglobin concentration to normal. Her diabetes mellitus was controlled on oral tolbutamide.

\section{Progress}

She remained well until July 1973 when she was re-admitted to hospital because her haemoglobulin had fallen to $4.9 \mathrm{~g} / 100 \mathrm{ml}$. She received blood transfusion and oral ferrous sulphate and remained well until November 1973 when she was re-admitted with vomiting and anaemia of $7 \cdot 2 \mathrm{~g} / 100 \mathrm{ml}$. At gastroscopy (Mr R. M. Kirk) a rigid non-peristaltic mass was seen in the pre-pyloric region and at laparotomy, a pyloric carcinoma with extensive hepatic and peritoneal metastases was found. Gastro-jejunostomy was performed. Histology revealed an undifferentiated mucus-secreting adenocarcinoma with metastases to the draining lymph nodes.

\section{Discussion}

This patient demonstrates a number of known associations of Turner's syndrome including duplication of the urinary collecting system (Grumbach, 1971) and diabetes mellitus (Jackson et al., 1966). It is of interest that diabetes mellitus is also a recognized association of another abnormality of sex 
chromosomes, namely, Klinefelter's syndrome (Nielsen, 1966).

The literature on the development of malignancy in patients with sex-chromosome abnormalities is not very extensive. Indeed, there is as yet no convincing evidence that abnormalities of sex chromosomes predispose to the development of solid tumours except in the abnormal and rudimentary glands found in these conditions (Goldberg and Scully, 1967; Teter and Bockowski, 1967).

Leukaemia has been described in Turner's syndrome, but the association is not as well documented as in Down's syndrome. Pawliger, Barrow and Noyes (1970) reported one case of acute lymphoblastic leukaemia in a 20 -year-old female and Wertecki and Shapiro (1970) described two cases of acute myeloblastic leukaemia in $45 \mathrm{XO}$ mosaics occurring in a family with a high incidence of twin births.

A search of the literature has revealed no previous report of gastric carcinoma in Turner's syndrome. The connection, if any, between the two conditions must remain speculative, although the unusually early development of the tumour may suggest a genetic predisposition. A chlorhydria, now generally accepted as a pre-malignant condition, is a known association of Turner's syndrome (Grumbach, 1971) but unfortunately gastric acid studies were not performed in this patient.

\section{Acknowledgment}

I wish to thank Dr Nigel Compston for permission to publish this case report.

\section{References}

Goldberg, M.B. \& Scully, A.L. (1967) Gonadal malignancy in gonadal dysgenesis: Papillary pseudomucinous cystadenocarcinoma in a patient with Turner's syndrome. Journal of Clinical Endocrinology, 27, 341.

GrumbaCH, M.M. (1971) The syndrome of gonadal dysgenesis: Turner's syndrome. In: Cecil-Loeb Textbook of Medicine (Ed. by P. B. Beeson and W. McDermott), 13th edn, p. 1800. W. B. Saunders Co., Philadelphia.

JaCKSON, I.M.D., Buchanan, K.D., McKiddie, M.T. \& PrentiCe, C.R.M. (1966) Carbohydrate metabolism and pituitary function in gonadal dysgenesis (Turner's syndrome). Journal of Endocrinology, 34, 289.

NiELSEN, J. (1966) Klinefelter's syndrome and diabetes mellitus. Lancet, ii, 748.

Pawliger, D.F., Barrow, M. \& Noyes, W.D. (1970) Acute leukaemia and Turner's syndrome. Lancet, i, 1345.

TETER, J. \& BockowSKI, K. (1967) Occurrences of carcinoma in dysgenetic gonads. Cancer (N.Y.), 20, 1301.

WERTECKI, W. \& SHAPIRo, J.R. (1970) Acute leukaemia and Turner's syndrome. Lancet, i, 789.

Postgraduate Medical Journal (June 1975) 51, 412-416.

\section{Secondary syphilis presenting with jaundice}

\author{
B. K. BHOWMICK \\ M.D., M.R.C.P.
}

\author{
S. P. B. WAY* \\ M.D., B.S., M.R.C.P. \\ Department of Medicine, Burton Road Hospital, Dudley, Worcestershire and \\ * Department of Pathology, Dudley, Stourbridge and District H.M.C.
}

\author{
B. SIMPSON \\ B.Sc., Ph.D., M.B., Ch.B.
}

\section{Summary}

A patient with secondary syphilis presenting with jaundice is reported. Hepatic histology showed evidence of non-specific granuloma and active hepatitis but no cholestasis. This has been treated successfully with antisyphilitic therapy. The possibility of syphilitic pancreatitis and diabetes mellitus is discussed. The importance of serological tests for syphilis in jaundice of obscure origin is emphasized.

\section{Introduction}

The secondary stage of syphilis has always been a diagnostic problem because of protean manifestations. Syphilitic hepatitis is rare and has received scanty attention in the literature. Few histological studies have been reported (Parker, 1972). Hahn
(1943) in a review of the literature could find only eighty cases of hepatitis among 33,825 patients with early syphilis, though in none was the association between the liver disease and the syphilis clearly demonstrated (Baker et al., 1971). Lee, Thornton and Conn (1971) mentioned that they were able to collect only six more patients with early syphilitic hepatitis since 1943. We describe here the case of a patient with secondary syphilis who presented with diabetes mellitus, maculopapular cutaneous rash and jaundice emphasizing the bizarre behaviour of the illness.

\section{Case report}

A 56-year-old white male patient was admitted in March 1973, complaining of tiredness, thirst and 